\title{
Decreasing Trend in Rainfall over Indochina during the Late Summer Monsoon: Impact of Tropical Cyclones
}

\author{
Hiroshi G. TAKAHASHI \\ Frontier Research Center for Global Change (FRCGC), \\ Japan Agency for Marine-Earth Science and Technology (JAMSTEC), Yokohama, Japan \\ and \\ Tetsuzo YASUNARI \\ Frontier Research Center for Global Change (FRCGC), \\ Japan Agency for Marine-Earth Science and Technology (JAMSTEC), Yokohama, Japan \\ Hydrospheric Atmospheric Research Center (HyARC), Nagoya University, Nagoya, Japan
}

(Manuscript received 14 May 2007, in final form 28 January 2008)

\begin{abstract}
We examined the decreasing trend in rainfall during the late summer monsoon season (September) in Thailand from 1951 to 2000 and associated changes in tropical cyclone (TC) activity. Thailand receives significant rainfall from May to October and experiences two rainy peaks in late May to early June and in September. A previous study reported a decreasing trend in September rainfall in Thailand and, based on a regional climate model, suggested that the trend was associated with local deforestation. However, the long-term trend may also be affected by changes in large-scale circulation. Thus, the purpose of this study was to investigate changes in large-scale circulation associated with the decreasing rainfall trend.

Westward-propagating TCs from the South China Sea and the western North Pacific brought most of the rainfall over Thailand in September. TCs include tropical depressions, tropical storms, severe tropical storms, typhoons, and residual lows. $70 \%$ of the rainfall amount in September was estimated to be associated with TCs.

The 50-year time-series of September rainfall over Thailand showed a significant decreasing trend. TC activity defined by $700-\mathrm{hPa}$ relative vorticity, showed a weakening trend over the Indochina Peninsula. TC tracks also suggested the weakening of TC activity over this area. The long-term trend in rainfall during the late summer monsoon season was closely associated with changes in TC activity over the Indochina Peninsula; these changes were likely caused by changes in the major course of TCs. Concurrent with the changes in TC tracks, there was a change in the TC steering current around the Philippines archipelago and Taiwan. This led to the TC activity over the Indochina Peninsula being inactive, probably resulting in the long-term decrease in rainfall over Thailand.
\end{abstract}

Corresponding author: Hiroshi G. Takahashi, Frontier Research Center for Global Change, Japan Agency for Marine-Earth Science and Technology, 3173-25 Showamachi, Kanazawa-ku, Yokohama City, Kanagawa 236-0001, Japan.

E-mail: hiroshi3@jamstec.go.jp

(C2008, Meteorological Society of Japan

\section{Introduction}

The hydrological cycle is an essential component of the climate system and is crucial for understanding global as well as regional climate change. In the Indochina Peninsula region, Kanae et al. (2001) examined the long-term trend in rainfall 
over Thailand in terms of land-atmosphere interaction and found that September rainfall showed a decreasing trend from 1951 to 1994. Interestingly, the long-term decreasing trend in rainfall was significant only in September. Based on the results of a regional climate model, they suggested that this decrease may be attributable to changes in land surface conditions and argued that deforestation has selectively decreased evapotranspiration and rainfall in September. The reason why other months did not show the decreasing trend in rainfall may be related to the seasonal march of monsoon circulations. Because the monsoon westerlies transport much more water vapor to the Indochina Peninsula during the mature stage of the summer monsoon season, the effects of land-atmosphere interaction could be weaker than in September. Thus, Kanae et al. (2001) concluded that deforestation across northeastern Thailand had probably caused the long-term decreasing trend in rainfall. However, long-term climate change at the regional scale may also be affected by long-term changes in large-scale circulations.

Over the past decade, numerous studies have examined the monsoon over the Indochina Peninsula. Numerous features distinguish the seasonal march of the summer monsoon over Indochina from those of the adjacent Indian, South China Sea, and western North Pacific monsoons (Matsumoto 1997; Zhang et al. 2002; Kiguchi and Matsumoto 2005; Takahashi and Yasunari 2006). Matsumoto (1997) showed two seasonal rainfall peaks in Thailand during the monsoon period. Takahashi and Yasunari (2006) reported that the first rainy peak, in late May to early June, is associated with strong monsoon southwesterlies, and the second rainy peak, in mid-August to mid-September, is probably influenced by tropical cyclone (TC) activity. Previous studies (e.g., Krishnamurti et al. 1977; Saha et al. 1981; Chen and Chen 1993) have shown that the monsoon depressions over the Bay of Bengal and the Indian subcontinent are closely related to westward-propagating disturbances that cross the Indochina Peninsula and originate from the South China Sea and western North $\mathrm{Pa}$ cific. Fudeyasu et al. (2006) reported that August and September are the most active months for westward-propagating TCs around the Indochina Peninsula. Furthermore, sub-monthly time-scale disturbances also move westward from the South China Sea to the Bay of Bengal and are associated with convective activity over the Indochina Penin-

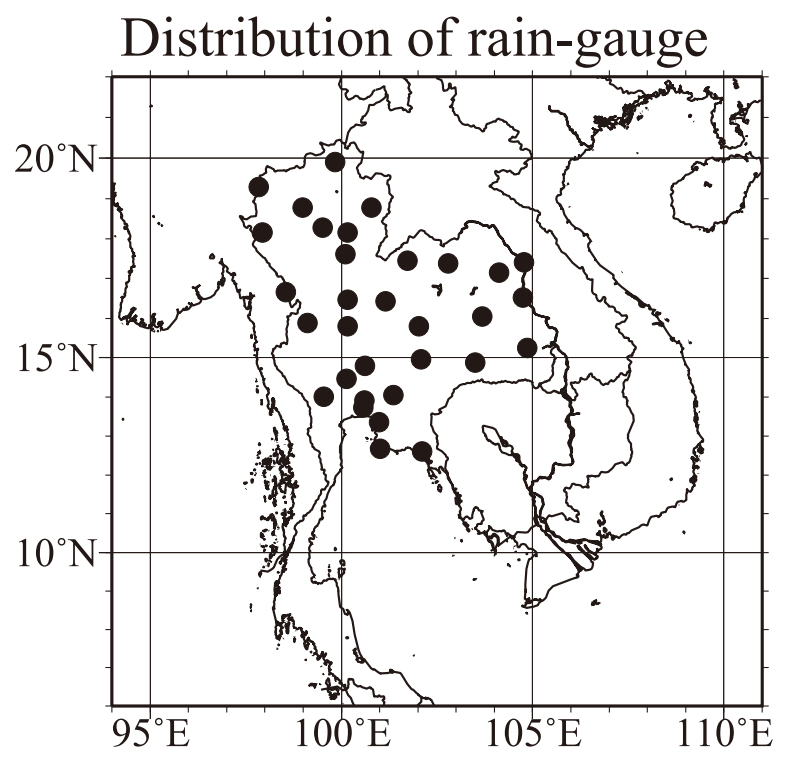

Fig. 1. Distribution of rain-gauge stations in Thailand.

sula (Fukutomi and Yasunari 1999) and rainfall in Thailand (Yokoi and Satomura 2005). Over the Indochina Peninsula, westward-propagating disturbances, which include tropical depressions, tropical storms, and sub-monthly disturbances, may be essential for rainfall variations in September.

We investigated atmospheric circulations associated with rainfall variations over the Indochina Peninsula in September. The primary purpose was to address the long-term decreasing trend of September rainfall over Thailand from the perspective of changes in TC activity and related largescale atmospheric circulations.

Section 2 documents the data used in this study. Section 3 describes the characteristics of atmospheric circulation associated with rainfall variation over Thailand in September. Long-term changes in rainfall and TC activity are examined in Section 4. Changes in the steering current of TCs are discussed in Section 5, and a summary is given in Section 6.

\section{Data}

The data used in this study were daily precipitation data measured from 1951-2000 in Thailand at 32 stations operated by the Thai Meteorological Department (TMD), as used by Takahashi and Yasunari (2006). We used domain-averaged rainfall. Figure 1 shows the distribution of rain-gauge stations. Changes in the atmospheric circulation were 
investigated using the 40-year Reanalysis (ERA-40, Uppala et al. 2005) dataset of the European Centre for Medium-Range Weather Forecasts (ECMWF). TC track data were provided by the Japan Meteorological Agency (JMA) and the Joint Typhoon Warning Center (JTWC). Although JTWC track data include weak TCs, such as tropical depressions, the quality of weak TC data is not homogeneous over the 50-year study period, making these data difficult to use for long-term trend analysis. Thus, we did not use the weak TC data in the JTWC TC track dataset. We describe the results from JMA TC track data; the same results were obtained from JTWC TC track data. Differences in TC track data before and after meteorological satellite operation were checked. The numbers of TCs formed over the western North Pacific in September were 64, 78, and 77 in 1951-1965, 1966-1980, and 1981-1995, respectively. These periods will be explained in Section 4. Before around 1965, TC numbers may have been underestimated; however, the underestimation would have no practical impact on the results of this paper.

\section{TCs and rainfall variations over the In- dochina Peninsula during September}

\subsection{Westward-propagating disturbances associated with rainfall variations during the late sum- mer monsoon}

To investigate atmospheric circulations associated with rainfall variations in Thailand during September, Fig. 2 presents a lag-composite analysis of low-level circulation anomalies. The anomalies of low-level circulation are departures from September climatological means (for 43 years). When the rainfall amount over Thailand on a given day exceeded one standard deviation from the mean, that day was qualified as a high-rainfall day and defined as a Lag 0 day in the lag-composite analysis. Of 1290 days, 190 were qualified as highrainfall days. Lag-composite analysis of low-level circulation was conducted based on the rainfall over Thailand. As shown in Fig. 2, cyclonic circulation was located over the Indochina Peninsula on Lag 0 day, indicating that rainfall variation over Thailand in September was associated with large-scale cyclonic circulation. On Lag -2 day, the cyclonic circulation was located over the South China Sea. On Lag -1 day, the cyclonic circulation migrated westward. The cyclonic circulation gradually migrated westward from the South China Sea to the Bay of Bengal across the Indochina Penin-

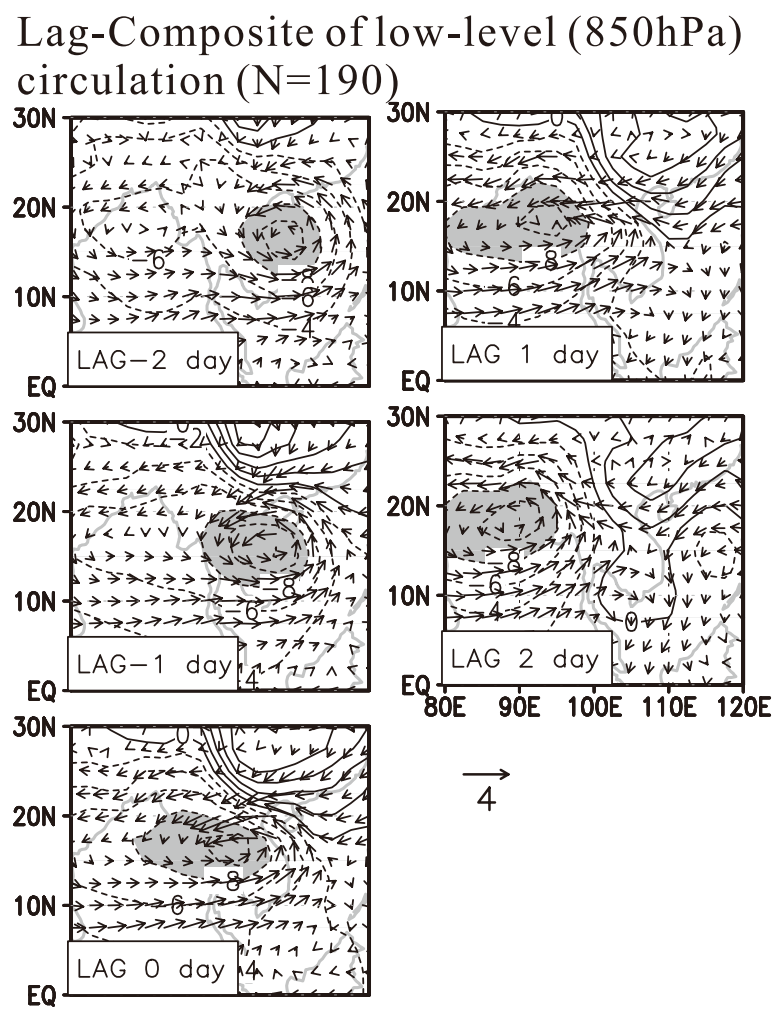

Fig. 2. Lag-composite map of daily $850-\mathrm{hPa}$ wind (vector) and geopotential height (contours) anomalies. The anomalies are departures from the 43-year September mean of each variable. Of 1290 days, 190 were composites. High rainfall days on which the rainfall amount exceeded one standard deviation from the mean were selected. Gray shading indicates that geopotential height anomalies were less than $-8 \mathrm{gpm}$.

sula. Therefore, rainfall variation over Thailand during September was strongly affected by westward-propagating disturbances. Note the zonal enlargement of cyclonic circulation, suggesting that rainfall does not always peak when the cyclonic circulation is located just over Thailand. Moreover, note that examination of the daily $850-\mathrm{hPa}$ wind field and TC tracks shows that the westwardpropagating disturbances include several types of disturbances (i.e., tropical depressions, tropical storms, severe tropical storms, typhoons, and residual lows). Hereafter, the term "TC" is used to indicate all of these types of tropical disturbances unless otherwise noted. 


\subsection{Detection of the TCs using reanalysis}

As discussed in the previous subsection, daily rainfall variation of Thailand during September was closely associated with westward-propagating TCs. As also noted above, "TC" includes not only tropical storms, which would be recorded in TC track data, but also weaker TCs, such as tropical depressions and residual lows. To estimate the effect of TCs on rainfall, a new TC index was necessary and is defined in this subsection.

September corresponds to the withdrawal of the Indochina monsoon (Wang and LinHo 2002) and thus a dramatic seasonal change in winds and geopotential heights. Because of filter noise, highpass and band-pass filtered winds and geopotential heights cannot detect TCs when the mean state drastically changes. To identify the TCs around the Indochina domain during September, $700-\mathrm{hPa}$ relative vorticity was used, following the method of Fudeyasu et al. (2006). Relative vorticity of 700 $\mathrm{hPa}$ was selected because $850-\mathrm{hPa}$ relative vorticity is affected by the friction in the planetary boundary layer, while $700-\mathrm{hPa}$ relative vorticity is not strongly affected. To detect most TCs, including those weaker than a tropical storm, the criterion was set to $3.0 \times 10^{-5} \mathrm{~s}^{-1}$. Fudeyasu et al. (2006) set their criterion value to $5.0 \times 10^{-5} \mathrm{~s}^{-1}$. However, that value could not detect weaker TCs. A criterion of $4.0 \times 10^{-5} \mathrm{~s}^{-1}$, did not detect weaker westwardpropagating TCs, while at a criterion of $2.0 \times 10^{-5} \mathrm{~s}^{-1}$, TCs were difficult to distinguish from noise. After much trial and error, the criterion of $3.0 \times 10^{-5} \mathrm{~s}^{-1}$ was determined. In addition, we confirmed that the TCs defined by $700-\mathrm{hPa}$ relative vorticity basically corresponded to convective activity estimated from outgoing longwave radiation (not shown). If any grid of the $700-\mathrm{hPa}$ relative vorticity exceeded $3.0 \times 10^{-5} \mathrm{~s}^{-1}$ within the Indochina domain (97.5$\left.107.5^{\circ} \mathrm{E}, 12.5-22.5^{\circ} \mathrm{N}\right)$, a $\mathrm{TC}$ was considered to exist over the domain. A day on which a TC existed within the Indochina domain is referred to as a TC-day.

As an example of the relationship between TCdays and daily rainfall variation, Fig. 3 shows the time-series of TC-days and daily rainfall variation for September 1993. The star symbols in the left panel, which shows the TC-day index defined by $700-\mathrm{hPa}$ relative vorticity, indicate the existence of a TC in the Indochina domain. The right panel shows the daily variation in rainfall over Thailand. September 1993 was a normal year in terms of rainfall amount over Thailand and TC activity over

\section{TC-day Rainfall}

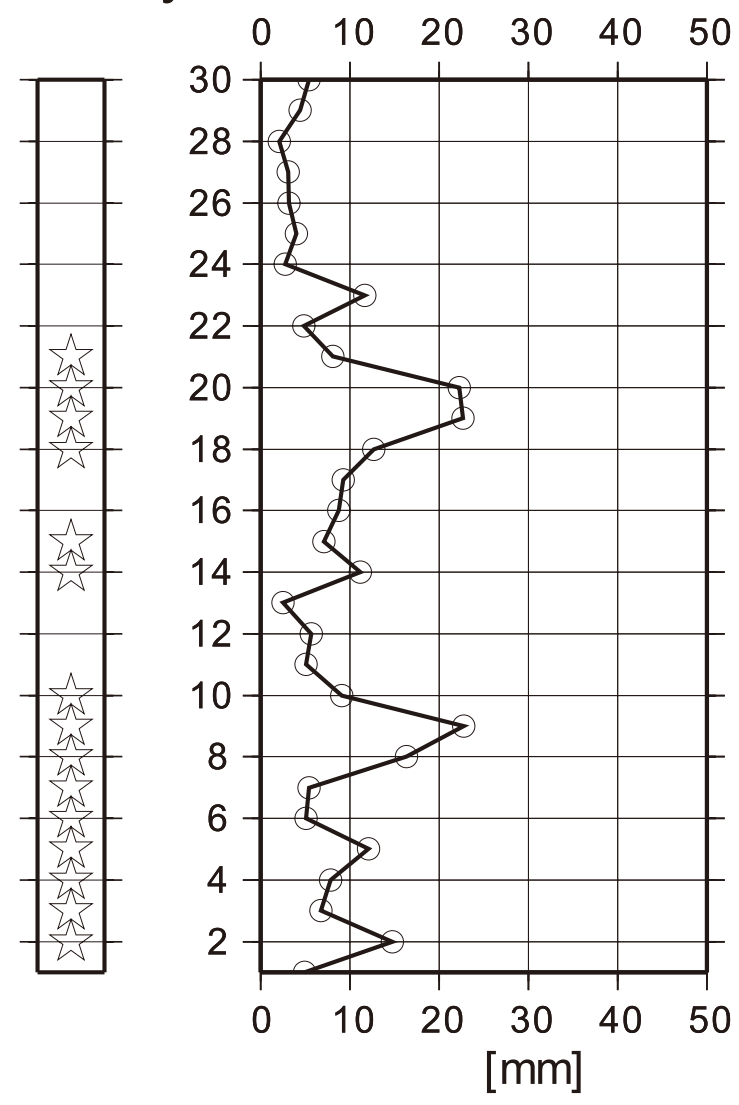

Fig. 3. TC index (left panel), defined by the relative vorticity at $700 \mathrm{hPa}$, as explained in the text, and time-series of daily rainfall over Thailand (right panel). Panels are for September of a typical year (1993).

the Indochina Peninsula. As shown in Fig. 3, TCdays had good agreement with daily rainfall variation, which again confirms that the daily rainfall over Thailand is strongly affected by TCs.

As an example of TC detection, Fig. 4 shows the time sequence of the total fields of 700-hPa relative vorticity (shaded), 850-hPa winds, and geopotential heights in September 1993. Strong cyclonic circulation was observed over the Indochina Peninsula from 2 to 4 September. The TC corresponded to the rainy peak on 2 September in Fig. 3. From 5 to 10 September, a clear cyclonic vortex migrated northwestward from the South China Sea to the Bay of Bengal (Fig. 4), which also corresponded to the rainy peak on 8 and 9 September (Fig. 3). The weak cyclonic circulation went across the 

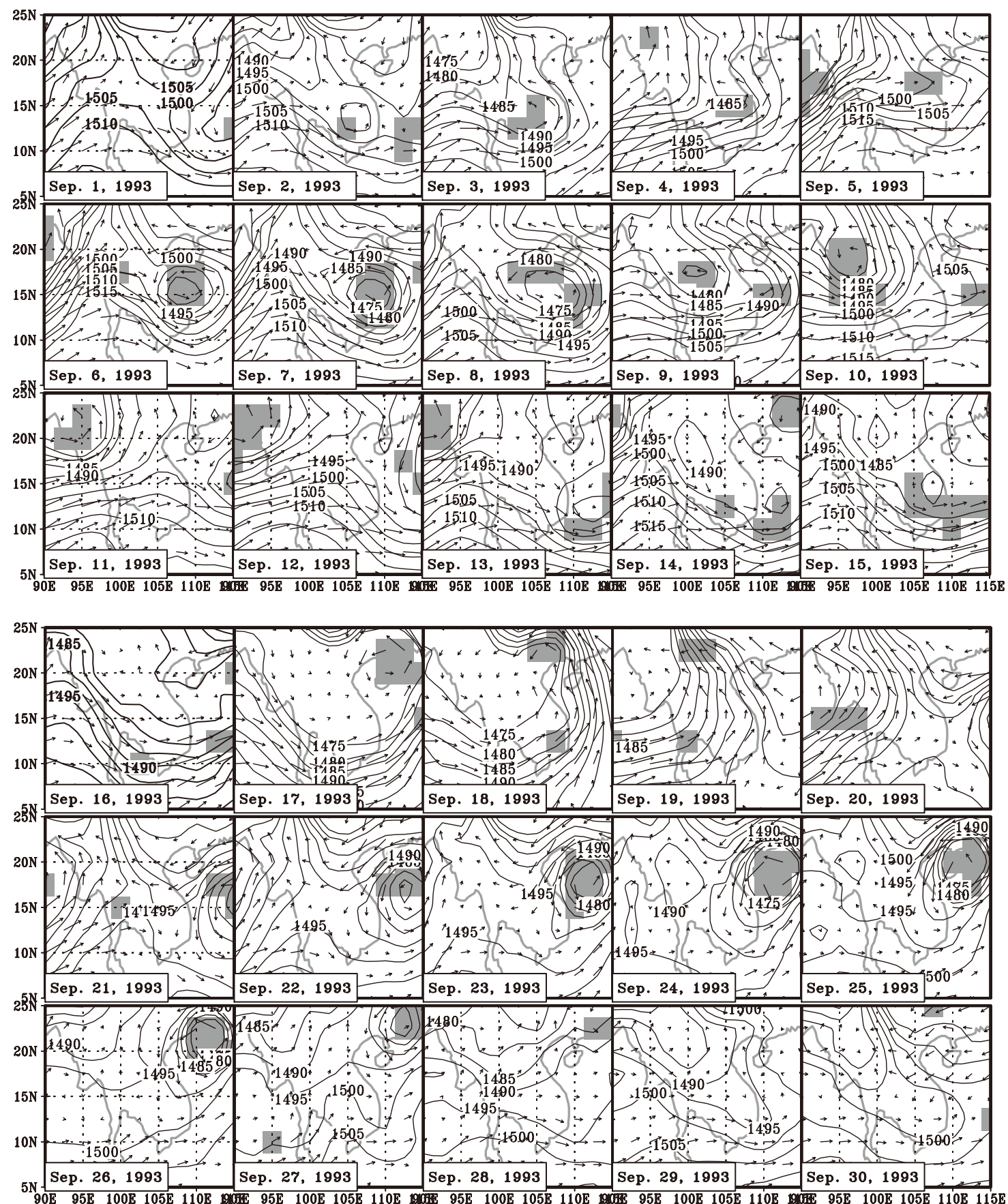

Fig. 4. Time-sequence of $700-\mathrm{hPa}$ relative vorticity (shaded) and $850-\mathrm{hPa}$ winds and geopotential heights (contours) in September 1993. Shading indicates that relative vorticity at $700 \mathrm{hPa}$ exceeds 3.0 $\times 10^{-5} \mathrm{~s}^{-1}$.

southern tip of the Indochina Peninsula on 14 and 15 September (Fig. 4), when rainfall was observed (Fig. 3). From 18 to 20 September, the larger cyclonic circulation passed through the Indochina
Peninsula (Fig. 4). The rainy peak on 19 and 20 September coincided with the passage (Fig. 3). In this manner, when the criterion for $700-\mathrm{hPa}$ relative vorticity was set $3.0 \times 10^{-5} \mathrm{~s}^{-1}$, most TCs were 
detected over the Indochina domain. Note that the westward-propagating TCs were almost consistent with rainfall variations. It is more noteworthy that the weak cyclonic circulations, which were not categorized as tropical storms in TC track data, were associated with large amount of rainfalls, implying that they are also quite important for the rainfall variation over Thailand.

\subsection{Contribution of TCs to total rainfall}

To quantify the contribution of westward-propagating TCs to rainfall over Thailand, TC-rain was defined as the proportion of rainfall amount from TCs to the total rainfall amount for Thailand. TCrain was defined according to TC-day; that is, TCrain indicates the rainfall amount associated with TC activity. TC-rain was estimated as the total rainfall over Thailand on all TC-days.

The climatological mean (43 years) TC-rain was $5.97 \mathrm{~mm} \mathrm{day}^{-1}$, which was about $68.5 \%$ of the total rainfall. In the study period, 730 TC-days were qualified, comprising $56.6 \%$ of the total analyzed days. Approximately seven-tenths of September rainfall was brought by the TCs, indicating that the rainfall associated with TCs is quantitatively essential to the rainfall in September over Thailand. Long-term changes of TC activity and atmospheric circulations will be investigated in the following section.

\section{Long-term changes in rainfall and TC activity}

Figure 5 shows interannual variations in September rainfall from 1951 to 2000. A long-term decreasing trend is prominent, as reported by Kanae et al. (2001). The nonparametric Mann-Kendall test (Press et al. 1992) was applied to the timeseries of the rainfall data, following the methods of Kanae et al. (2001), and the test reconfirmed the significant decrease in rainfall. The 50-year study period was divided into three periods (1951-1965, 1966-1980, and 1981-1995, referred to as P1, P2, and P3, respectively) to facilitate examination of TC activity changes associated with the long-term trend in rainfall over Thailand and to discuss the decreasing trend noted by Kanae et al. (2001). Periods $\mathrm{P} 1, \mathrm{P} 2$, and $\mathrm{P} 3$ had mean rainfall amounts of $9.73,9.02$, and $7.85 \mathrm{~mm} \mathrm{day}^{-1}$, respectively.

To investigate the relationship between the rainfall amount over Thailand and TC activity over the Indochina Peninsula, Fig. 6 shows a scatter plot of September rainfall over Thailand and TC-

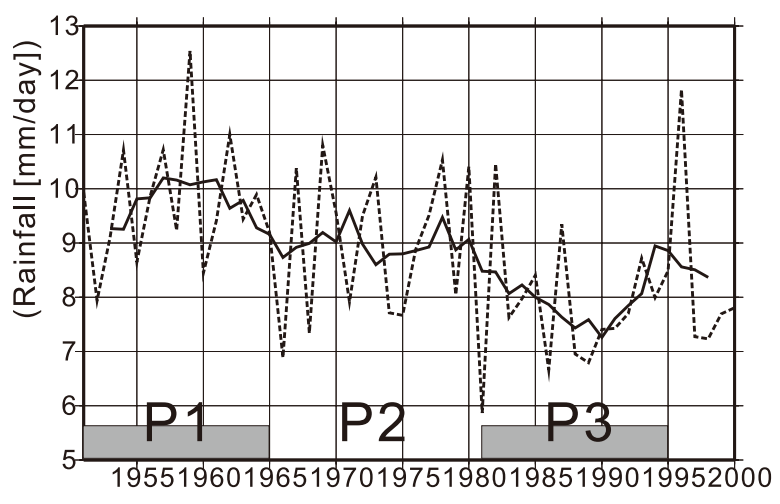

Fig. 5. Interannual variation of September rainfall over Thailand for 1951-2000. The dashed (solid) line shows the original time-series (5-year running mean) of rainfall. P1 (1951-1965), P2 (1966-1980), and P3 (1981-1995) are shown in the panel. Unit is $\mathrm{mm} \mathrm{day}^{-1}$.

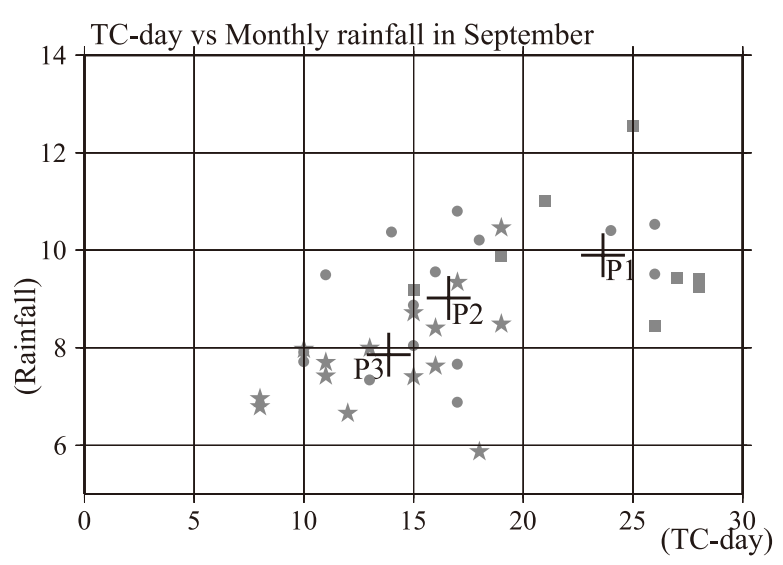

Fig. 6. Scatterplot between September rainfall over Thailand and TC day defined by $700-\mathrm{hPa}$ relative vorticity. Rectangle, circle, and star symbols indicate the relationship in each year during P1, P2, and $\mathrm{P} 3$, respectively. The crosses labeled P1, P2, and P3 show the mean relationship of each period. There were fewer samples for P1 than for the other two periods because of limitations of the ERA-40 dataset.

day. Rectangle, circle, and star symbols show the relationship in each year during $\mathrm{P} 1, \mathrm{P} 2$, and $\mathrm{P} 3$, respectively. Crosses with $\mathrm{P} 1, \mathrm{P} 2$, and $\mathrm{P} 3$ denote the mean relationships of each period. The sample number for P1 was smaller than those of the other two periods because of limitations of the ERA-40 

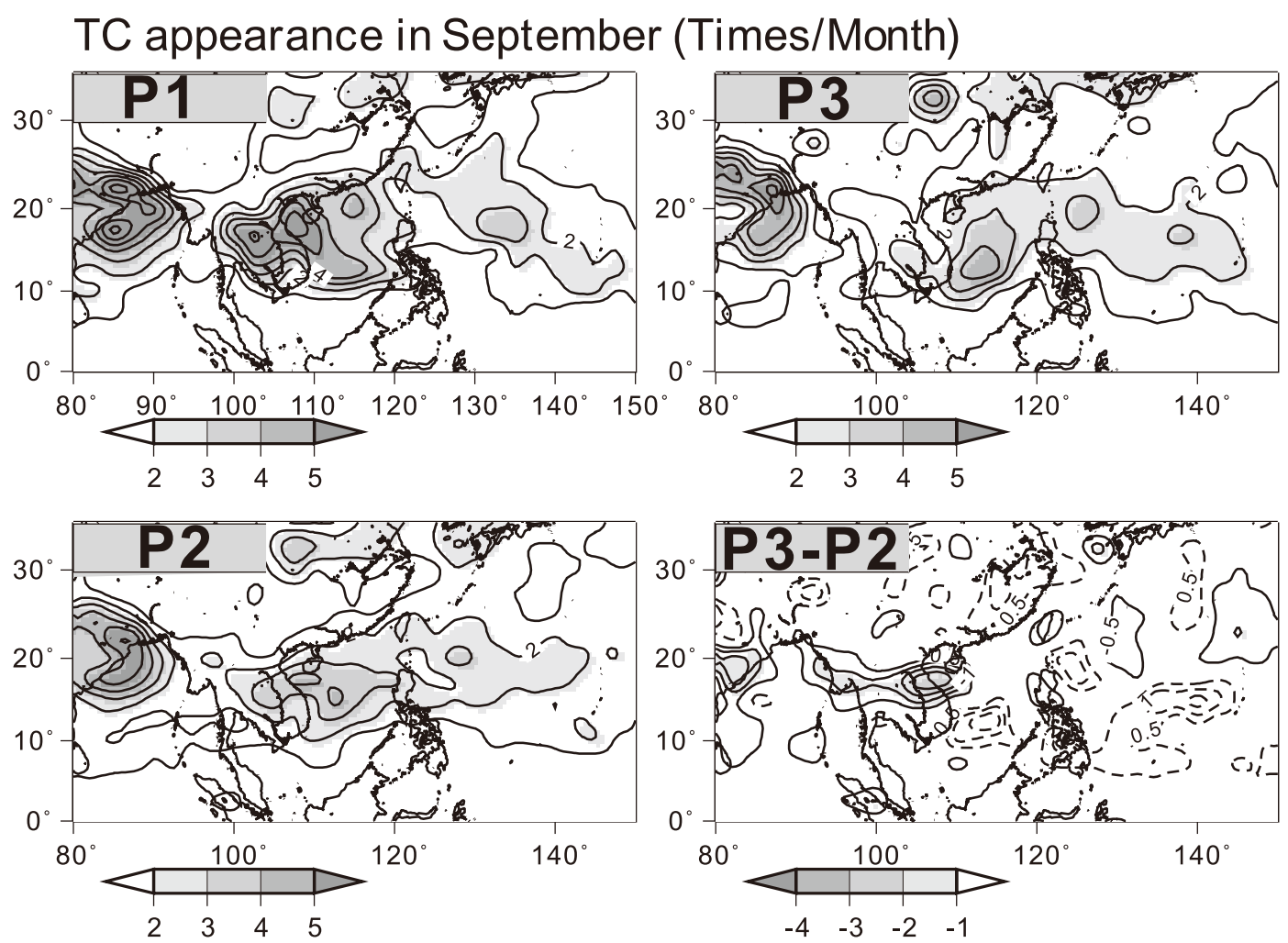

Fig. 7. TDistribution of TC-appearance frequencies during P1, P2, and P3 and the difference between P2 and P3 (i.e., P3 minus P2). As in Fig. 6, P1 had fewer samples than the other two periods. In the difference map, the shading shows the area with values less than -1 . Unit is times per month. The contour interval for $\mathrm{P} 1, \mathrm{P} 2$, and $\mathrm{P} 3$ is one time per month. The contour interval of the right lower panel is 0.5 times per month.

dataset. The correlation coefficient between rainfall and TC-day for the 43 years from 1958 to 2000 was 0.56 , which is significant at the $99 \%$ confidence limit. This result implies that TC-day, which is basically associated with TC activity over the Indochina Peninsula, is closely related to rainfall variation in Thailand on an interannual timescale. Chen and Yoon (2000) pointed out that the number of TCs was correlated with rainfall during the whole summer rainy season on an interannual time-scale, which is consistent with our result. Figure 6 shows the crosses moving toward lower rainfall with less frequent TC-days over time, implying that rainfall and TC activity have decreased over the Indochina Peninsula. Therefore, this result clearly demonstrates that changes in TC activity over Thailand are consistent with the long-term decreasing trend of rainfall.

Figure 7 shows the spatial distribution of the frequencies of TC appearance. As for TC-day, a
TC was considered to exist at the grid when the $700-\mathrm{hPa}$ relative vorticity exceeded $3.0 \times 10^{-5} \mathrm{~s}^{-1}$ for that grid. Also as in Fig. 6, P1 had less samples than P2 or P3. All three periods showed high frequencies of TC appearance over the Bay of Bengal, South China Sea, and western North Pacific (Philippine Sea). Note that the high frequencies of TC appearance over the Bay of Bengal and western North Pacific are consistent with the monsoon depressions and TC activity in those respective areas. In P1 and P2, areas of high-frequency TC appearance expanded westward from the South China Sea to the Indochina Peninsula. TC frequency was higher in P1 than in P2 over the Indochina Peninsula. Distributions were similar around the Indochina Peninsula, but high-frequency TC appearance was not observed over the Indochina Peninsula in P3. The difference map shows that TC-appearance frequencies over the Indochina Peninsula clearly became lower, suggesting that 
westward-propagating TCs decreased over the Indochina Peninsula from P2 to P3. On the other hand, higher frequencies of TC appearance were observed over the southern South China Sea and Philippine Sea to China, which probably indicates increases in TCs there from P2 to P3. In this manner, TC activity over the Indochina Peninsula weakened from P1 to P2 and from P2 to P3. In addition, we also checked the weaker criteria for TCappearance of $2.0 \times 10^{-5} \mathrm{~s}^{-1}$ and $1.0 \times 10^{-5} \mathrm{~s}^{-1}$. The difference of TC-appearance of the weaker criteria showed the same tendency. Thus, we concluded that the number of the westward propagating TC have decreased over the Indochina Peninsula.

Figure 8 shows TC tracks in each period, illustrating changes in the motion of TCs. For this figure, JMA TC track data in September in each period were plotted. The TC track data do not include TCs weaker than a tropical storm. In P1 and P2, major clusters of TC passage over the South China Sea and western North Pacific were observed as southeast-northwest-oriented bands. Over the South China Sea, most TCs propagated westward or west-northwestward. Some landed over the Indochina Peninsula and some approached the peninsula. Interestingly, the TC passage during P3 over and around the South China Sea was clearly different from that in P1 and P2. Westward or west-northwestward-propagating TCs over the South China Sea were not dominant during P3. In P3, TCs moved more northward or took a weaving course over the South China Sea. In addition, more TCs were observed over southern China in P3. Consequently, only a small number of TCs made landfall or approached the Indochina Peninsula in P3.

Furthermore, it is noteworthy that the long-term changes in JMA TC tracks (Fig. 8) are consistent with the long-term changes in the frequency of TC appearance (Fig. 7), derived from ERA-40 data. The two independent parameters, namely TC appearance derived from ERA-40 and JMA TC tracks, yielded a similar result, implying that TC activity over the Indochina Peninsula very likely became increasingly inactive from P1 to P2 and from P2 to P3. From P1 to P2, the frequency of TC appearance simply became lower over the Indochina Peninsula. From P2 to P3, the major course of TCs changed over the Philippines archipelago and South China Sea, indicating that a small number of TCs made landfall or approached the Indochina Peninsula in P3. Thus, the weakening trend of

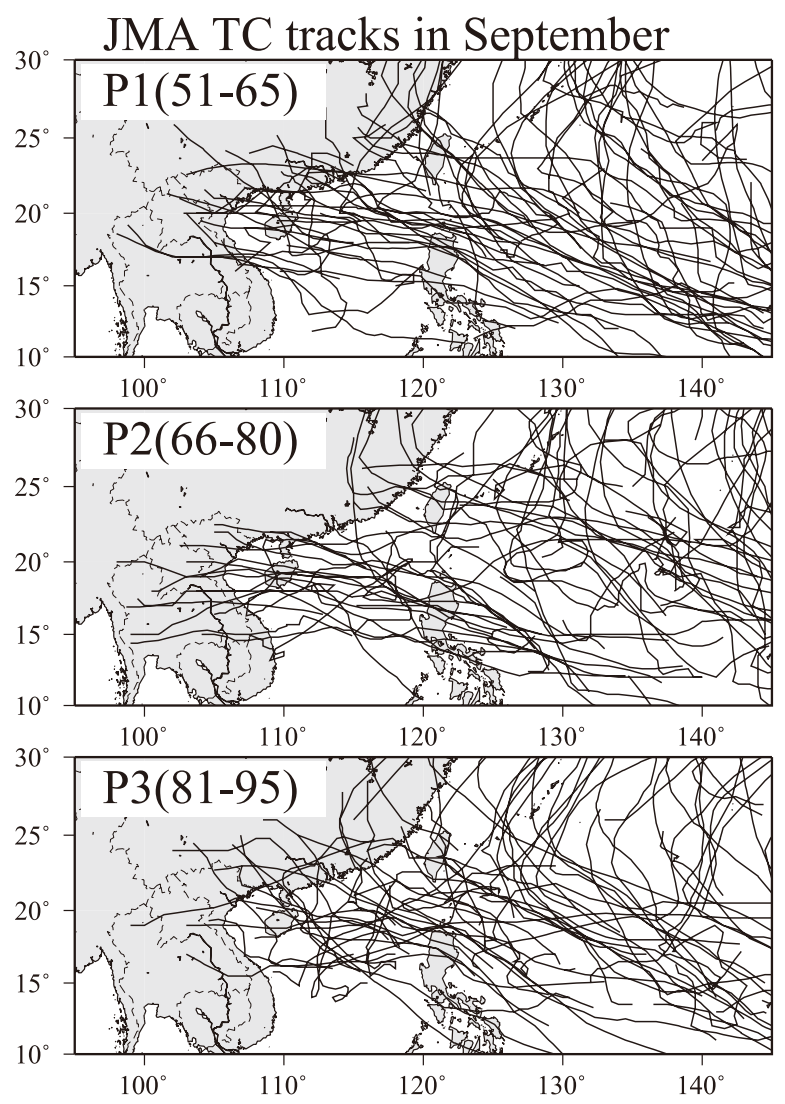

Fig. 8. JMA TC tracks in September during $\mathrm{P} 1, \mathrm{P} 2$, and P3. Some tracks start from the midstream of the lifetime of a TC, while other tracks end in the midstream. Only TC tracks in September were plotted. JMA TC tracks do not include TCs weaker than a tropical storm.

TC activity over the Indochina Peninsula is likely responsible for the long-term trend of rainfall over Thailand.

\section{Large-scale circulation}

The previous section discussed the likely association between changes in TC activity (Figs. 6 and 7) and changes in the major course of TCs from P2 to P3 (Fig. 8). Mid-tropospheric flow (700 $\mathrm{hPa}-500 \mathrm{hPa}$ ) can be considered the steering current of TC motion (e.g., Chan and Gray 1982). Experience shows that the best altitude of TC motion is around $4-5 \mathrm{~km}$ (Emanuel 2005). To discuss differences in the changes of TC tracks, Fig. 9 shows winds and geopotential height at $600 \mathrm{hPa}$. However, before discussing these differences, the quality of ERA-40 data should be noted. 

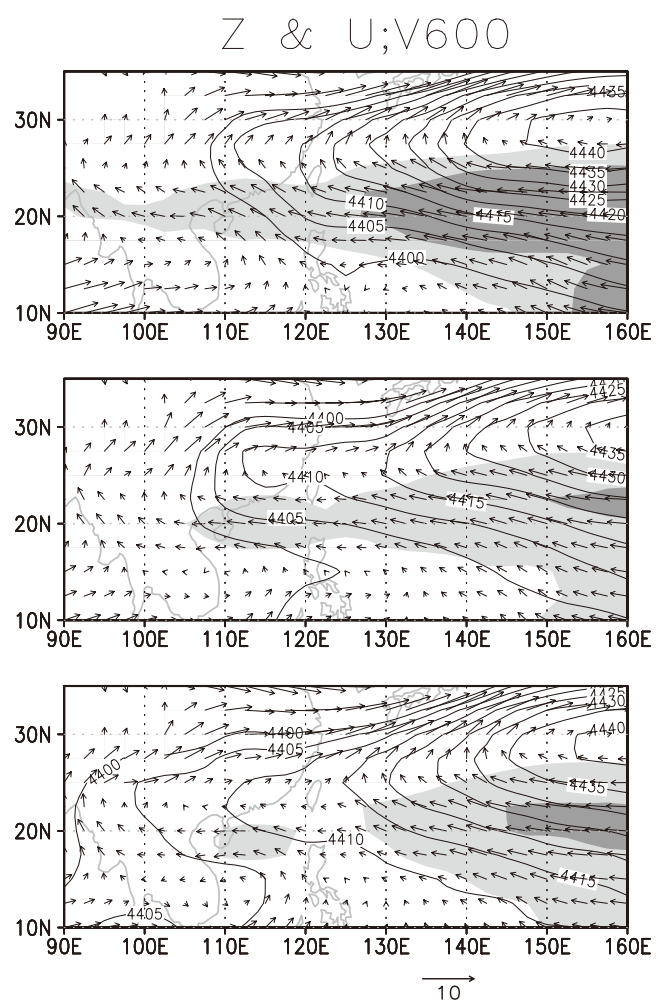

Fig. 9. Monthly mean geopotential heights (contours) and winds (vectors) at 600 $\mathrm{hPa}$ in each period. There were fewer samples for P1 than for the other two periods. The shading indicates that easterly winds were stronger than $2 \mathrm{~m} \mathrm{~s}^{-1}$.

Some satellite data were available after 1973, with satellites in full-scale operation after 1979. Thus, gaps are likely in ERA-40 around 1973 and 1979. Because the time-series of the 600-hPa geopotential height and winds over the South China Sea and western North Pacific showed no strong gaps (not shown), ERA-40 can be used to show long-term changes in mid-tropospheric circulation around the South China Sea and western North Pacific. Again, the sample number for P1 was smaller than the sample numbers for the other two periods. As shown in Fig. 9, easterlies along the periphery of the subtropical high were dominant over the western North Pacific and South China Sea during P1 and P2. Easterlies penetrated from the western North Pacific to the Indochina Peninsula. The region of easterlies (Fig. 9) was consistent with the region where the westward propagation of TCs was dominant in P1 and P2 (Figs. 7 and 8). On the other hand, the mid-tropospheric easterlies were very weak over the Philippines and Taiwan during P3, which could suggest that the westward steering current for TC motion was weaker than in the other periods. This result corresponded to the observed small number of TCs propagating westward to the Indochina Peninsula and the weaving course of TCs over the South China Sea (Fig. 8). The changes in the mid-tropospheric circulations were not inconsistent with the changes in TC activity. Therefore, the weakening of TC activity from P2 to P3 over the Indochina Peninsula can be explained by changes in the courses of TCs, which were probably consistent with the changes in midtropospheric large-scale circulation.

\section{Summary}

We investigated the long-term decreasing trend in rainfall over Thailand in the late summer monsoon season, using daily rainfall from Thailand, JMA and JTWC TC tracks, and the ERA-40 Reanalysis dataset. Thailand usually experiences a rainy peak in September. September rainfall over Thailand was strongly influenced by TCs propagating westward from the South China Sea and western North Pacific to the Indochina Peninsula. The westward-propagating TCs included several types of westward-propagating tropical disturbances, such as tropical depressions, tropical storms, severe tropical storms, typhoons, and residual lows. When TCs were defined by $700-\mathrm{hPa}$ relative vorticity, about $70 \%$ of rainfall over Thailand was brought by TCs in September.

The 50-yr time-series of September rainfall showed a long-term decreasing trend. The frequency of TC-days over the Indochina Peninsula, derived from 700 -hPa relative vorticity, decreased from P1 to P2 and from P2 to P3 and was significantly correlated with rainfall variation over Thailand. JMA TC tracks showed that westward- and west-northwestward-propagating TCs were dominant in P1 and P2. However, P3 had fewer westward-propagating TCs over the Indochina Peninsula compared to P1 and P2. Two independent parameters, namely TC appearance derived from ERA-40 and JMA TC tracks, showed weakening of TC activity over the Indochina Peninsula. From P1 to P2, the frequency of TCs simply decreased. Changes in TC activity from P2 to P3 over the Indochina Peninsula were caused by changes in the major course of TCs over the South China Sea. Changes in the major course of TCs were likely associated with changes in steering currents over 
the Philippines archipelago and Taiwan. Therefore, we concluded that the long-term decreasing trend in September rainfall over Thailand has been caused by changes in TC activity over the Indochina Peninsula and South China Sea.

Our results have demonstrated that the weakening of TC activity over the Indochina Peninsula is probably a significant factor in the long-term decrease in September rainfall over Thailand. Kanae et al. (2001) proposed that deforestation over northern Thailand has caused long-term decreases in rainfall through a decrease of surface evapotranspiration. Further study will include comprehensive comparison of changes in land surface effects and TC activity, using a regional climate model.

\section{Acknowledgments}

Rainfall data were kindly provided by the Thai Meteorological Department through GEWEX (Global Energy and Water Cycle Experiment) Asian Monsoon Experiment (GAME)-Tropics (GAME-T). We would like to acknowledge two anonymous reviewers for helpful suggestions and comments. We would like to thank Dr. H. Fujinami, HyARC, Nagoya University for grateful comments and continuous encouragements. We thank Dr. N. Endo of IORGC, JAMSTEC for valuable comments and suggestions. We are grateful to Prof. J. Matsumoto of Tokyo Metropolitan University for valuable comments. Some figures were made with the Generic Mapping Tools (GMT) graphics system developed by Wessel and Smith in 1995. This work was partly supported by the Global Environment Research Fund (B-061) of the Ministry of the Environment, and Ministry of Education, Culture, Sports, Science and Technology (MEXT), Japan.

\section{References}

Chan, J.C.L. and W.M. Gray, 1982: Tropical cyclone movement and surrounding flow relationship. Mon. Wea. Rev., 110, 1354-1374.

Chen, T.-C. and J.-M. Chen, 1993: The 10-20-day mode of the 1979 Indian monsoon: Its relation with the time variation of monsoon rainfall. Mon. Wea. Rev., 121, 2465-2482.

Chen, T.-C. and J.-H. Yoon, 2000: Interannual variation in Indochina summer monsoon rainfall: Possible mechanism. J. Climate, 13, 1979-1986.

Emanuel, K.A., 2005: Divine Wind-The History and Science of Hurricanes. Oxford Univ. Press, 285 pp.
Fudeyasu, H., S. Iizuka, and T. Matsuura, 2006: Seasonality of westwardpropagating disturbances over southeast and south asia originated from typhoons. Geophys. Res. Lett., 33, doi:10.1029/2005GL025380.

Fukutomi, Y. and T. Yasunari, 1999: 10-25 day intraseasonal variations of convection and circulation over east asia and western north pacific during early summer. J. Meteor. Soc. Japan, 77, 753-769.

Kanae, S., T. Oki, and K. Musiake, 2001: Impact of deforestation on regional precipitation over the Indochina Peninsula. J. Hydrometeor, 2, 51-70.

Kiguchi, M. and J. Matsumoto, 2005: The rainfall phenomena during the premonsoon period over the Indochina Peninsula in the GAME-IOP year, 1998. J. Meteor. Soc. Japan, 83, 89-106.

Krishnamurti, T.N., J. Molinari, H. Pan, and V. Wong, 1977: Downstream amplification and formation of monsoon disturbances. Mon. Wea. Rev., 105, 1281-1297.

Matsumoto, J., 1997: Seasonal transition of summer rainy season over Indochina and adjacent monsoon region. Adv. Atmos. Sci., 14, 231-245.

Press, W.H., S.A. Teukolsky, W.T. Vetterling, and B.P. Flanner, 1992: Numerical Recipes in C: The art of scientific computing. Cambridge University Press, 2 edition, $994 \mathrm{pp}$.

Saha, K., F. Sanders, and J. Shukla, 1977: Westward propagating predecessors of monsoon depressions. Mon. Wea. Rev., 109, 330-343.

Takahashi, H.G. and T. Yasunari, 2006: A climatological monsoon break in rainfall over Indochina - A singularity in the seasonal march of the Asian summer monsoon -. J. Climate, 19, 1545-1556.

Uppala, S., P. Kallberg, A. Simmons, U. Andrae, V. da Costa Bechtold, M. Fiorino, J. Gibson, J. Haseler, A. Hernandez, G. Kelly, X. Li, K. Onogi, S. Saarinen, N. Sokka, R. Allan, E. Andersson, K. Arpe, M. Balmaseda, A. Beljaars, L. van de Berg, J. Bidlot, N. Bormann, S. Caires, F. Chevallier, A. Dethof, M. Dragosavac, M. Fisher, M. Fuentes, S. Hagemann, E. Holm, B. Hoskins, L. Isaksen, P. Janssen, R. Jenne, A. McNally, J.-F. Mahfouf, J.-J. Morcrette, N. Rayner, R. Saunders, P. Simon, A. Sterl, K. Trenberth, A. Untch, D. Vasiljevic, P. Viterbo, and J. Woollen, 2005: The ERA-40 re-analysis. Quart. J. Roy. Meteor. Soc., 131, 2961-3012.

Wang, B. and LinHo, 2002: Rainy season of the AsianPacific summer monsoon. J. Climate, 15, 386-398.

Yokoi, S. and T. Satomura, 2005: An observational study of intraseasonal variations over southeast asia during the 1998 rainy season. Mon. Wea. Rev., 133, 20912104.

Zhang, Y., T. Li, B. Wang, and G. Wu, 2002: Onset of the summer monsoon over the Indochina Peninsula: Climatology and interannual variations. J. Climate, 15, 3206-3221. 